\title{
SIGNIFICADO DE LABORATÓRIOS DE ENSINO DE HISTÓRIA DE IES PÚBLICAS SOB A CONCEPÇÃO DA DIDÁTICA DA HISTÓRIA E EDUCAÇÃO HISTÓRICA
}

\author{
MEANING OF HISTORY TEACHING LABORATORIES OF HIGHER \\ EDUCATION INSTITUTIONS UNDER THE CONCEPTION OF \\ HISTORY DIALECTICAL AND HISTORICAL EDUCATION
}

Marilu Favarin Marin ${ }^{1}$

\begin{abstract}
RESUMO: Pretende um estudo sobre Laboratórios de Ensino de História (doravante denominados LEH), ligados a cursos de graduação em História de Universidades Públicas, que foram criados entre o período de tempo de 1980 a 1990. Este recorte selecionou os LEH das seguintes Universidades brasileiras: Universidade Federal de Santa Maria/RS; Universidade Estadual de Londrina/Pr, Universidade Federal de Uberlândia/MG e Universidade Federal Fluminense/RJ. Entre os objetivos propostos pretende-se: investigar a criação dos LEH fazendo um estudo comparativo dos mesmos; investigar, relacionar e analisar os produtos gerados pelos LEH no período entre as décadas de 1980 e 2010; e, apresentar discussão sobre quais seriam os fundamentos de uma concepção de LEH a partir de uma didática da história fundamentada na educação histórica, verificando a relação entre teoria e didática da história.
\end{abstract}

Palavras-Chaves: Laboratórios de história. Didática da história. Educação histórica.

\begin{abstract}
You want a study on teaching History Teaching Laboratories (called LEH) which are linked to graduation courses in History at Public Universities. These courses were created between 1980 and 1990. The current study selected the LEH of the Brazilian Universities that follows: Universidade Federal de Santa Maria/RS, Universidade Estadual de Londrina/PR, Universidade Federal de Uberlândia/MG and Universidade Federal Fluminense/RJ. Among the proposed aims, it intends to investigate the LEH's creation through a comparative study of them; analyze the generated products by LEH in the period between 1980 and 2010 decades; and to present a discussion about which are the foundations of a LEH conception from a history's didactic based on historical education, checking the relation between theory and history's didactic.
\end{abstract}

Keywords: History Laboratories. Didactic of history. Historical education.

\footnotetext{
${ }^{1}$ Professora da Universidade Federal de Santa Maria - Campus Silveira Martins/RS e doutoranda do Programa de Pós-Graduação em Educação da Universidade Federal do Paraná
} 


\section{Introdução}

Esta proposta de tese teve como origem o estudo realizado durante o Curso de Mestrado em Educação, do Programa de Pós-Graduação em Educação da Universidade Federal de Santa Maria, no período entre 1995 e 1997. A referida investigação foi um estudo de caso realizado sobre as experiências de professores de História de escola pública de Ensino Médio, em Santa Maria/RS-Brasil, e da qual havia participado, entre os anos de 1988 a 1991, primeiramente como acadêmica monitora e depois estagiária da licenciatura. A experiência que foi investigada se desenvolveu entre 1988 e 1997 - período de apogeu da transição democrática no Brasil, e que foi intensamente marcado por inovações no campo da educação. Conhecida como Projeto Piloto, se pautou na revisão do ensino de História tomando como base uma concepção críticadialógica, e foi orientada pelo Laboratório de Ensino de História da então Faculdade de História, da Universidade Federal de Santa Maria/RS - Brasil.

Realizada essa investigação, nos anos seguintes dedicados à docência no ensino superior no Centro de Educação da mesma Universidade Federal, na área de Políticas Públicas em Educação, trabalhou-se com alunos dos diferentes cursos de licenciatura, entre eles os do Curso de História, o mesmo pelo qual se obtivera graduação no ano de 1991. O trabalho com acadêmicos e docentes do agora Curso de História da UFSM favoreceu a continuidade do acompanhamento da caminhada do Laboratório de Ensino de História do referido curso, cuja trajetória julga-se importante relatar brevemente.

$\mathrm{Na}$ proposta inicial, o referido Laboratório de Ensino de História, criado em 1988, objetivava: retomar os debates sobre questões relativas ao ensino e aprendizagem na disciplina de História; articular estratégias, especialmente no processo de ensino e aprendizagem, que favorecessem a retomada da significância da disciplina de História nas escolas públicas de Educação Básica, significância que durante e após o período histórico da ditadura militar, no Brasil (1964-1981), fora (e ainda o é em grande parte dos currículos escolares) relegada a uma posição marginal nos currículos escolares; qualificar a formação de novos professores, 
oportunizando e aprofundando trocas entre acadêmicos estagiários e professores atuantes no espaço da escola básica; consolidar-se como polo articulador de novos encaminhamentos para o ensino da História, da produção de novos conhecimentos e de ruptura com a hegemonia do ensino tradicional, favorecendo assim a formação continuada dos professores de história da rede pública regional; oportunizar o acesso e conhecimento às novas produções na área de História, assim como fomentar o debate, no plano teórico- metodológico, das novas produções, as quais já eram alvo de intensos debates em instituições de ensino superior, públicas e privadas, assim como em outras instituições, desde o início do período histórico da abertura política, especialmente a partir do final da década de 1970.

No encaminhamento desses objetivos o grupo que atuava no Laboratório ${ }^{2}$ desenvolveu trabalho apoiado no projeto institucional "O Ensino da História: uma proposta em construção I", o qual teve, desde sua criação até meados da década de 2000, dez edições, sendo que depois de 1995 a coordenação do mesmo passou para novos docentes, recém chegados à IES devido a aposentadorias ocorridas no grupo criador do Laboratório $^{3}$. Durante a década de 2000, seguindo o percurso do Laboratório através de atividades acadêmicas, foi possível constatar que o projeto inicia, apoiado principalmente na renovação do ensino de história e no aprofundamento da relação Universidade-Escola Básica, fora mantido até o final da década de 1990.

No ano de 2007, a participação em evento da área da pesquisa em ensino de história - o VI Encontro Nacional Perspectivas do Ensino de História, entre 10 e 13 de outubro, na cidade de Natal, no Rio Grande do Norte, possibilitou assistir a conferência de abertura proferida pela Profa. Dra. Maria Auxiliadora Moreira dos Santos Schmidt, da Universidade Federal do Paraná. O tema da conferencia apontou novas possibilidades no ensino de história e fez algumas referencias aos

\footnotetext{
${ }^{2}$ Faziam parte do primeiro grupo alguns docentes da Faculdade de História e um docente do Departamento de Metodologia do Ensino do Centro de Educação, alunos da graduação em História e docentes de história da rede pública regional.

${ }^{3}$ A maior parte dessas aposentadorias foi motivada por mudanças promovidas pelo governo federal no plano de carreira do magistério superior
} 
laboratórios de ensino no processo formativo. Contatos posteriores e participação em estudos e debates na Universidade Federal do Paraná favoreceram o conhecimento sobre novas produções ${ }^{4}$, novos olhares sobre cultura, educação e escola, assim como a leitura e estudo de Jörn Rüsen, importante teórico alemão que desenvolve trabalho sobre a Didática da História e as possibilidades de uma didática própria da ciência histórica fundamentada na educação histórica. Foi importante verificar nos autores estudados a necessidade de construir uma prática pedagógica não só apoiada nas disciplinas acadêmicas dos cursos de história, mas também subsidiada pelo debate a cerca de "como se pensa a história, quais são as origens da história na natureza humana, e quais são seus usos para a vida humana" (RÜSEN, 2006, p. 8), considerados aí saberes e fazeres que a realidade cotidiana disponha.

$\mathrm{Na}$ sequencia deste quadro foi construído $\mathrm{o}$ projeto de doutoramento aprovado na seleção de Doutorado do Programa de PósGraduação em Educação da UFPR, que tem como temática central o "Significado de Laboratórios de Ensino de História de IES públicas sob a concepção da Didática da História e da Educação Histórica". Por ele retomou-se, como objeto de investigação, as diretrizes e práticas de Laboratórios de Ensino de História. Nesse contexto, a partir de março de 2009, a problemática foi se estruturando, delineando-se nas orientações a proposição de investigar pressupostos que permitam fazer um estudo comparativo entre laboratórios de Ensino de História de Instituições de Ensino Superior públicas; investigar e catalogar a produção desses Laboratórios ao longo de sua existência; e, construir um conceito de Laboratório de Ensino de História à luz da didática da história, fundamentada esta na educação histórica. A necessidade de fazer uma delimitação de tempo na problemática resultou pela definição de estudo dos Laboratórios de Instituições de Ensino Superior (públicas) que haviam sido criados nas décadas de 1980-1990, e isso resultou num recorte que definiu quatro Laboratórios, três em instituições federais e um em

4 Jean-Claude Forquin, Raymond Williams, Clifford Geertz, Pierre Bourdieu, Anthony Giddens, Michael Apple, Jörn Rüsen, são alguns autores de obras ou fragmentos destas às quais tive acesso no ano de 2008 
instituição estadual. Sobre a hipótese levantada, tomando como ponto de partida a experiência do Laboratório de Ensino de História da Universidade Federal de Santa Maria e o que se delineou depois dele no próprio curso, aponta-se para uma relação entre conhecimento científico e processo de ensino aprendizagem no âmbito prescritivo, ou seja, seguindo a linha da transposição didática. Há que considerar que os outros Laboratórios de Ensino de História que estão sendo alvo do estudo possam ter essa mesma perspectiva, ou não.

Assim, este estudo de doutorado toma como base a compreensão da existência de uma "didática da história", e vem se construindo especialmente pelos estudos da produção do teórico alemão Jörn Rüsen. Do estudo de sua produção está sendo possível compreender que a didática da história é o campo de análise dos fundamentos da educação histórica, e cumpre papel central no processo de reflexão nas atividades dos historiadores. Deste modo, a problemática está enunciada da seguinte forma: Quais seriam os pressupostos de um conceito de Laboratório de Ensino de História em instituições de ensino superior públicas tendo como referência a didática da histórica fundamentada na educação histórica?

\section{Desenvolvimento Parcial da Temática}

Acredita-se que o problema definido possibilitará investigar uma possibilidade de relação entre os Laboratórios pesquisados, como eles estão sendo pensados na atualidade, e qual a relação com a concepção de didática da história e educação histórica. Também se acredita ser necessário tentar perceber como acontece nestes as relações entre teorias da história e didática, melhor dizendo, a relação entre o conhecimento científico e o processo de ensino e aprendizagem.

Para tanto, organizou-se um instrumento de investigação que permita aos investigados manifestarem-se com liberdade, através da "entrevista semiestruturada" (FLICK, 2009, p. 148-149). Este tipo de instrumento de coleta de dados possibilita um caráter de interação entre entrevistador e entrevistado, criando uma ambiente de reciprocidade, 
aceitação e estimulo entre os mesmos, um clima de confiança mútua, de legitimidade de ambos, favorecendo que as informações sejam mais autênticas e sinceras. A entrevista semiestruturada não é rígida nem impositiva, corroborando para que o entrevistado discorra livremente sobre o assunto, com base em informações e experiências de vida. Quando necessário, o investigador poderá intervir para evitar que o entrevistado se distancie do tema.

Também, de acordo com Lüdke e André (1996),

\begin{abstract}
A grande vantagem da entrevista sobre outras técnicas é que ela permite a captação imediata corrente da informação desejada, praticamente com qualquer tipo de informante e sob os mais variados tópicos. Uma entrevista bem feita pode permitir o tratamento de assuntos de natureza estritamente pessoal e intima, assim como temas de natureza complexa e de escolhas nitidamente individuais. Pode permitir o aprofundamento de pontos levantados por outras técnicas de coleta de alcance mais superficial como o questionário. (LÜDKE; ANDRÉ, 1996, p. 43).
\end{abstract}

Neste sentido, a definição por este tipo de instrumento de coleta de dados mostra-se coerente com a metodologia proposta neste trabalho, apoiada no enfoque qualitativo, pois devido à flexibilidade empregada, permite um aprofundamento gradativo no tema pretendido.

Considera-se que, apesar de estar longe da rigidez técnica, a entrevista semi- estruturada não prescinde de cuidados e sensibilidade aguçada no trato com o entrevistado e com os instrumentos utilizados para o registro desta. Em relação a esses instrumentos, está se usando a gravação com forma de registro, pois mesmo que com ela se perca o gestual, os olhares, a comunicação corporal, a gravação permite maior fidedignidade às falas dos entrevistados. A aplicação da entrevista é precedida da organização de um roteiro informal com o objetivo de evitar que se percam informações. Nos Laboratórios, estão sendo entrevistados docentes e acadêmicos, conforme a seguinte ordenação: docentes que participaram da criação do Laboratório e que continuam atuando no mesmo; docentes que atuam no mesmo, mas que não participaram do processo de criação; docente que participaram da criação do Laboratório, 
masque não estão mais atuando no mesmo; acadêmicos que participaram da criação do Laboratório e que atuam ou não em ações ligadas ao mesmo; e, acadêmicos que não participaram da criação do Laboratório, mas que atuam em ações ligadas ao mesmo.

$\mathrm{Na}$ continuidade tomando como foco de estudo o Laboratório que deu origem ao estudo de mestrado e cujo acompanhamento auxiliou na definição do estudo de doutorado, aplicou-se aí entrevistas semiestruturadas (FLICK, 2009), as quais permitiram adiantar algumas observações sobre o contexto atual. No decorrer da década de 2000, sob nova coordenação e novas diretrizes curriculares, as atividades relacionadas à formação dos licenciados se concentraram em novos componentes curriculares aglutinados em Núcleos de Pesquisa, e embora o antigo Laboratório não tenha sido extinto ele não tem mais um público envolvido e, consequentemente não desenvolve mais atividades relacionadas à formação dos acadêmicos do curso ${ }^{5}$. Deste modo, nos Núcleos de Pesquisa há enfoques em: Arqueologia; História e Saúde; História da América; História e Literatura; História e Cinema; Movimentos Sociais no Brasil; Educação e Memória. Posteriormente foram criados Núcleo de Pesquisa em Teoria e Ensino de História I e II. $^{6}$ Estes dois Núcleos, assim como os demais, fazem parte da chamada estrutura curricular flexível. No caso destes, o número de alunos matriculados é pequeno, em torno de cinco a dez por semestre, o que pode levar a concluir que, no presente momento, o interesse por temas e estudos ligados a licenciatura também seja pequeno.

Sobre os conteúdos pedagógicos específicos para o ensino de história, os Laboratórios de Prática de Ensino em História I, II, III e IV, tem os seguintes objetivos, relacionados consecutivamente:

\footnotetext{
${ }^{5}$ É importante destacar que o novo currículo em questão mantém a tradicional segmentação no que diz respeito à formação para a pesquisa e a formação para o ensino dos acadêmicos. A formação para o ensino continua tendo os componentes curriculares desenvolvidos por professores dos departamentos didáticos do Centro de Educação da UFSM.

6 Desenvolveu-se atividades de ensino nesses dois núcleos, no primeiro e segundo semestres de 2009 a convite de um docente do Curso e com a aprovação do Colegiado deste, com o intuito de introduzir novas leituras e debates que pudessem contribuir para aproximar a formação dos licenciados de novas interpretações sobre o ensino e a didática da história. Para tanto, foram usadas fontes como Forquin, Williams, Eagleton, Geertz, Chavellard.
} 
- Criar materiais didáticos relacionados à História Antiga e Medieval, com o fim de tanto aprender a adequar os conteúdos ao ensino fundamental e médio como meio de facilitar o ensino-aprendizagem; Produzir materiais didáticos relacionados à América e o Brasil do período anterior ao século $\mathrm{XIX}$, os quais possam auxiliar na prática do ensino fundamental e médio;

- Produzir materiais didáticos relacionados ao mundo contemporâneo, dirigidos para a História Mundial, da América e do Brasil Contemporâneos, os quais possam auxiliar na prática do ensino de história no ensino fundamental e médio;

- Preparar os acadêmicos na produção de aulas e de recursos técnicos e teóricos para trabalhar com os cursos de extensão, alfabetização de jovens e adultos ${ }^{7}$.

A bibliografia prevista compreende obras relacionadas aos conteúdos dos períodos históricos que são o foco da ementa em cada Laboratório. Na bibliografia ligada à didática, no Laboratório I, há apenas uma obra que se refere ao tema, de José Alberto Baldissera ${ }^{8}$; no Laboratório II, as obras contemplam novamente Baldissera, além de Nidelcoff, Penteado, Pinsky e Silva ${ }^{9}$. No Laboratório de Prática de Ensino de História III, além das obras relacionadas aos conteúdos dos períodos históricos, as obras indicadas para a formação pedagógica são exatamente as mesmas do Laboratório II. No Laboratório IV, as obras são de educadores como Freire, Fagundez e Gadotti ${ }^{10}$.

A análise de conteúdo das entrevistas e um breve estudo sobre os objetivos propostos e as obras bibliográficas indicadas para alcançar esses objetivos permite inferir, num estágio inicial, que a formação para a prática docente se faz por uma concepção que toma a didática geral como parâmetro para os estudos nos Laboratórios de Prática e Ensino, uma vez

\footnotetext{
${ }^{7}$ Fonte: http://w3.ufsm.br/prograd/bachareladolicenciaturahistoria/curriculo.

8 BALDISSERA, J. A. O livro didático de história: uma visão crítica. Porto Alegre: Evangraf, 1994;

9 BALDISSERA, J. A. O livro didático de história: uma visão crítica. Porto Alegre: Evangraf, 1994; CABRINI, C. et al. O ensino de história. Revisão urgente. 2 ed. São Paulo: Brasiliense, 1986; NIDELCOFF, M. T. Uma escola para o povo. 12 ed. São Paulo: Brasiliense, 1981; A escola e a compreensão da realidade. 4 ed. São Paulo: Brasiliense, 1981; PENTEADO, H. D. Metodologia do ensino de história e geografia. São Paulo: Cortez, 1990; PINSKY, J. et al. O ensino de história e a criação do fato. São Paulo: Contexto, 1988; e, SILVA, M. (Org.). Repensando a história. São Paulo: Marco Zero, 1987.

${ }^{10}$ GADOTTI, M., ROMÃO, J. E. Educação de jovens e adultos: teoria, prática e proposta. São Paulo: Cortez, 2001. FReire, P., FAgUndeZ, A. Por uma Pedagogia da Pergunta. Rio de Janeiro: Paz e Terra, 1985. FREIRE, P. Educação como prática de liberdade. Rio de Janeiro: Paz e Terra, 2002.
} 
que o comum entre maioria destas obras, e que permite compreender qual a corrente teórica que perpassa a formação pedagógica desses licenciados, é a opção pelo que Rüsen (1987, p. 8) define como "opinião padrão sobre o que a didática da história é", ou seja, o status tradicional da didática da história como uma disciplina que faz parte da formação de professores de história e que é mediadora entre a transposição do conhecimento acadêmico para os ensinamentos de história na escola básica. Por esta compreensão, a didática do ensino história naquela Instituição vem contribuindo para desenvolver o ensino da história na escola e outras instituições, para ensinar história a crianças e jovens (e neste caso também na Educação de Jovens e Adultos - EJA), mas como um campo restrito, ou seja, não se relaciona com o trabalho dos historiadores no estudo do seu próprio campo.

Pela análise inicial as ações que haviam sido assumidas por este Laboratório de Ensino de História entre 1988 e 1995 (este ultimo ano é uma referencia não exatamente precisa), relativas aos objetivos já descritos no início desta apresentação temática, e que o colocava como um espaço de debates e trocas de experiências e produção, parecem ter ficado à margem do processo formativo dos acadêmicos do Curso de História, o qual pelo currículo atual forma os bacharéis licenciados. Além do mais, com exceção do Laboratório IV e das Práticas de Ensino ${ }^{11}$ que ocorrem a partir do sétimo semestre,o trabalho formativo está significativamente restrito ao espaço acadêmico da Universidade.

É importante destacar que no decorrer da década de 2000 se constituiu movimento importante em pesquisa do ensino da história, bastante divulgado e debatido em eventos da área ${ }^{12}$, de concepção de

\footnotetext{
11 As práticas de ensino acontecem a partir do sétimo semestre - o curso tem dez semestres, e compreendem uma sequencia, de: observações no Ensino Fundamental e Médio (70. Sem.); atividades voluntárias de cunho social fora da escola básica ( $8^{\circ}$. Sem.); atividades de ensino em caráter de extensão que podem acontecer em cursinho prévestibular, formação continuada de professores, cursos de atualização, cursos com a terceira idade (9o. Sem); e, planejamento e execução da proposta de trabalho no Ensino Fundamental e Médio (10. Sem.).

12 Refere-se a eventos na área de História promovidos por: Associação Nacional de História (ANPUH), com uma década de eventos em âmbito nacional e regional; Seminário Iberamericano de Didática das Ciências Sociais, na terceira edição; e, a eventos específicos da área de Ensino de História, tais como: Encontro Nacional de Pesquisadores do Ensino de História (ENPEH), com dez edições; Jornadas Internacionais de
} 
uma didática específica da ciência histórica, a exemplo do que vem ocorrendo na Europa Ocidental e que agregou pesquisadores ao redor de novas produções, especialmente a partir da obra de Jörn Rüsen "Didática da História: passado, presente e perspectivas a partir do caso alemão", de 1987, anteriormente referida. Nesta publicação, Rüsen afirma, ainda se referenciando a "opinião padrão" (...), pela qual "A didática da história serve como uma ferramenta que transporta conhecimento histórico dos recipientes cheios de pesquisa acadêmica para as cabeças vazias dos alunos" (RÜSEN, 1987, p. 8) de que esta interpretação resulta numa concepção enganosa do papel da mesma porque falha em pontos essenciais para a sua significância no processo educativo, a saber: falha em confrontar a educação histórica e os problemas reais do aprendizado da história; falha na relação entre a didática da história e a pesquisa histórica; e, falha na perspectiva dos historiadores em relação as suas práticas e aos princípios de sua disciplina, limitando-os ideologicamente.

Usando a interpretação de Rüsen (1987), traçada sobre o contexto europeu ocidental atual, e tentando aproxima-la da realidade educacional brasileira e do Curso em questão, assim como considerando depoimentos de acadêmicos estagiários sobre suas práticas de ensino, é perceptível que uma das problemáticas que estes últimos enfrentam diz respeito às dificuldades manifestas sobre "transportar"13 para a sala de aula da Educação Básica os conteúdos que aprenderam ao longo da sua formação.

Também é possível inferir, em caráter inicial, que esta situação é reforçada pelo distanciamento contínuo e crescente dos cursos de formação em relação à escola básica, processo já bem visível em 1993, um dos motivos que levaram à escolha do Laboratório de Ensino de História do Curso de História da UFSM/RS como objeto de investigação no Curso de Mestrado (1995-1997), delineando aí questões internas especialmente do espaço escolar, e questões externas - do contexto sóciohistórico e político, os quais se avaliaram que teriam contribuído para a

Educação Histórica, também com dez edições; Seminário de Educação Histórica, promovido pelo LAPEDUH/UFPR, e que se encaminha para a terceira edição neste ano de 2010

${ }^{13}$ Termo mais empregado pelos acadêmicos em suas manifestações a respeito do tema. 
desarticulação da proposta iniciada em 1988.

Considera-se importante destacar que na década que se seguiu à conclusão do mestrado (1998-2007), o distanciamento entre a instituição formadora e os docentes e seu trabalho nas escolas de educação básica, local por excelência das práticas didático-pedagógicas (e no recorte que interessa nesta proposta, dos professores de história), se acentuou e parece ter agravado a fragilidade no processo de formação de novos docentes, contribuindo para isso, entende-se, a reforma curricular de 2004, a qual centrou a formação do egresso no profissional chamado de bacharel licenciado. A reforma curricular parece não só não ter resolvido problemas pré-existentes na formação de docentes como aponta contribuições para o seu agravamento uma vez que é claro que, mesmo com a aura romântica que acompanha a profissão de historiador ${ }^{14}$, a maioria quase absoluta dos egressos não encontra absorção nessa área da ciência histórica, restando atuar como docente na escola básica, mesmo que sem o querer e sem o preparo necessário, fundamental para tão complexa profissão. Corrobora também para essa fragilidade a ruptura na relação entre academia e professores em exercício na escola básica, o que além de distanciar os formandos do conhecimento da realidade escolar e das suas práticas cotidianas, aprofunda as lacunas na formação continuada daqueles primeiros. Destaca-se esta questão por entender-se que a formação continuada seja um dos importantes compromissos das IES, não só para com os egressos de seus cursos, mas como para o conjunto de professores que atuam nas regiões do seu entorno.

Sobre a hipótese, tomando como ponto de partida essa experiência, inicialmente aponta-se para uma relação entre conhecimento científico e processo de ensino e aprendizagem no âmbito prescritivo, seguindo a linha da transposição didática. Sobre a Teoria da Transposição Didática encontrase referencial na obra do francês Ives Chavellard (2000), La Transposición didactica: del saber sabio al saber enseñado, publicada pela primeira vez em 1985 em versão francesa. A tese defendida por Chavellard, que se concentra no ensino da matemática, mostra-se significativa para

14 O emprego do termo 'profissão' considera o estágio de avanço do projeto que encaminha o reconhecimento e registro da profissão de historiador no Brasil, neste ano de 2010. 
compreender proposições que se efetivam na área da didática de qualquer dos campos do ensino. Segundo Ives Chavellard (2000), toda ciência deve ter como primeira condição o ser ciência de um objeto real cuja existência é independente do olhar que o transformará em objeto de conhecimento, carregando em si um determinismo próprio, uma necessidade que a ciência quererá descobrir. No caso da transposição didática, essa necessidade é definida como o sistema de ensino, o chamado sistema didático. Este é compreendido por Chavellard como um sistema de relações que envolvem docente, aluno e saber - uma relação ternária, sendo esta a base do pensar, o objeto da ciência da educação (no caso do presente trabalho, da educação histórica). Segundo o autor, por duas décadas pelo menos, na educação matemática, ( $e$, particularmente, entende-se que em outras áreas da educação escolar também) foi esquecido o terceiro componente desta relação, o saber. Sendo que atualmente vem sendo considerado, então Chavellard julga importante perguntar:

¿que és entonces aquello que, en el sistema didáctico, se coloca bajo el estandarte del Saber? El "saber enseñado" que concretamente encuentra el observador, ¿que relación entabla con lo que se proclama de él fuera de ese ámbito? ¿Y que relación entabla entonces con el "saber sabio", (...)? ¿ Qué distancias existen entre unos y otros? (CHAVELLARD, 2000, p. 15) ${ }^{15}$

O que é que no sistema didático se coloca sob o estandarte do saber? Ou seja, quais saberes são considerados tão significativos para serem eleitos, serem inclusos e comporem o elenco de conteúdos a ser ensinado na escola? O que o autor chama de "saber ensinado", que é algo concreto que ocorre na relação ternária - docente, aluno, saber, qual relação esse saber estabelece com o âmbito externo, ou seja, com a realidade vivenciada pelos alunos? Qual seria o seu significado, a sua validade na realidade presente? E que relação estabelece com o saber acadêmico, que Chavellard conceitua como "saber sábio"? Que distâncias existem entre "saber ensinado" e "saber sábio", melhor dizendo, entre os

${ }^{15}$ Grifos de autor

História \& Ensino, Londrina, v. 16, n. 1, p. 127-141, 2010 
conteúdos que foram eleitos para serem ensinados na escola e os conteúdos preferidos no ensino acadêmico?

Esses questionamentos são importantes para compreender se uma das grandes dificuldades dos professores da escola básica nos seus fazeres de ensino cotidianos, e que dizem respeito a tomar decisões sobre: quais os conteúdos significativos a ensinar; quais os conteúdos que podem ser excluídos sem prejuízo de compreensão durante o processo cognitivo; se os conteúdos incluídos darão conta dessa compreensão; como fazer as adequações ${ }^{16}$, como "transportar", necessidades justificadas pelas diferenças existentes entre o espaço acadêmico e o espaço escolar, entre outras. As adequações podem explicar de alguma forma o que acontece na sala de aula, na relação ternária entre docente, aluno e saber, e que se refere ao que Chavellard entende por transposição didática: a passagem do saber sábio para o saber ensinado como ferramenta que permite recapacitar, tomar distância, interrogar as evidências, questionar as ideias simples, desprender-se da familiaridade enganosa do objeto de estudo (CHAVELLARD, 2000, p. 16). Segundo ele, é o que permite exercer a "vigilância epistemológica", o cuidado com o conhecimento científico, sendo este um dos elementos de ruptura que a didática deve exercer para constituir seu próprio domínio científico. Para isso, ainda conforme Ives Chavellard se faz necessário quebrar a harmonia do sistema didático, o qual não depende da nossa vontade, pois o saber que se ensina, que ele denomina como saber ensinado, resulta diferente do que inicialmente se pretendeu que devia ensinar, da transposição do saber sábio,no contexto das relações entre docente, aluno e saber. As contribuições de Chavellard merecem continuidade de estudos, uma vez que se referem, muito proximamente, de incertezas bem conhecidas e presentes no fazer docente cotidiano.

16 Talvez a palavra "adequações" não seja a melhor, mas é exatamente isso que costumeiramente acontece na maioria das vezes, na educação escolar básica. 


\section{Considerações Finais}

Esse artigo tenta mostrar alguns passos de um estudo inicial sobre Laboratórios de Ensino de História. Bruno Ciari (1975), numa das raríssimas abordagens sobre "laboratórios de investigação científica" (CIARI, 1975, p. 141) no processo de ensino e aprendizagem, embora restrito ao âmbito da escola básica, escreve sobre o significado do trabalho em laboratório:

Um importante ponto de partida é que a criança seja posta em condições de empenhar directamente, sozinha ou em colaboração com outras, as suas capacidades de compreender e classificar, comparar e medir, estabelecer relações de interacção entre objectos e fenómenos, formular hipóteses, num processo de tentativas cada vez mais bem empreendidas, de erros, de correcções, de descobertas. Este modelo de aprendizagem, em que o professor assume 0 papel de estimulador, de formulador de sugestões, de coadjutor da actividade experimental do aluno (...). (CIARI, 1975, p. 141)

Fazendo uso da interpretação do autor, é possível visualizar no lugar do aluno criança o aluno acadêmico, em cujo processo de formação profissional se faz necessário romper com a abordagem prescritiva e abrir as possibilidades de exercício prático das potencialidades. Entendese que vivências assim no processo formativo poderiam alterar profundamente um modelo de formação prescritivo para o modelo reflexivo, crítico e autônomo. A contribuição de Ciari reforça a ideia dos Laboratórios como espaços de debate sobre experiências, incertezas, acertos e dificuldades que acadêmicos e professores de história tem nas suas vivências, seja no processo de formação seja no exercício da docência. É neste contexto que se entende a importância do estudo sobre as novas produções, especialmente as que abordam a relação ensino e aprendizagem, a relação entre as teorias e as práticas da educação histórica e a significância de uma didática própria da ciência histórica e da educação histórica na formação de pessoas para o "viver no mundo e com o mundo". 


\section{REFERÊNCIAS}

CHAVELLARD, Y. La Transposición Didáctica. Del saber sabio al saber enseñado. 3. ed., Traducción de Claudia Gilman. Buenos Aires: Aique Grupo Editor S.A., 2000.

CIARI, B. Práticas de Ensino. Lisboa: Editorial Estampa, 1979, p. 141-147.

EAGLETON, T. A idéia de cultura. Trad. de Sandra Castelo Branco. São Paulo: Editora UNESP, 2005.

FLICK, U. Introdução à Pesquisa Qualitativa. Trad. de Joice Elias Costa, 3. ed., Porto Alegre: ArtMed, 2009.

FORQUIN, J-C. Escola e cultura. Porto Alegre: Artes Médicas Sul, 1993.

GEERTZ, Clifford. Uma descrição densa: por uma teoria interpretativa da cultura. In A interpretação das Culturas. Rio de Janeiro: LTC, 1989.

LÜDKE, Menga e ANDRÉ, E. D. A. Pesquisa em educação: abordagens qualitativas. São Paulo: E.P.U. 1996.

RÜSEN, J. Didática da História: passado, presente e perspectivas a partir do caso alemão. Trad. de Marcos Roberto Kusnick. Práxis Educativa. Ponta Grossa, PR. V. 1, n. 2, p. 07 - 16, jul./dez. 2006

WILLIAMS, R. Cultura. Trad. de Lólio Lourenço de Oliveira. 2. ed., Rio de Janeiro: Paz e Terra, 1992.

Cultura e sociedade. São Paulo: Cia. Edit. Nacional, 1969. CURRÍCULO do Curso de História da UFSM. Disponível em http://w3.ufsm.br/prograd/bachareladolicenciaturahistoria/curriculo. 